\title{
Editorial
}

\section{Aortic root abscess}

Infective endocarditis affecting the aortic valve may be complicated by an abscess cavity in the aortic root, ${ }^{1-3}$ and this is more frequent and serious in prosthetic than native valve infections. ${ }^{45}$ Successful management of this condition, which has high morbidity and mortality, invariably requires surgical repair, and depends on early diagnosis, clear preoperative anatomical definition, and maintaining the sterility of the second implant. Homograft valves offer many advantages: they are resistant to infection, ${ }^{167}$ prosthetic material is not involved, and the abscess cavities can be excluded from the circulation. ${ }^{7-9}$ There are further potential advantages from the use of homografts in children. Experience with aortic root abscess in infants and children is very limited; Chaturvedi and colleagues describe their experience with five cases collected over 10 years at a supraregional referral centre, a testimony to the rarity of the condition in paediatric practice. ${ }^{10}$ We have little experience of this condition in children, and this review is based on experience gained in managing adults.

The terminology of aortic root abscess is rather misleading. Strictly speaking the uncontrolled infection causes a mycotic aneurysm of one of the sinuses of Valsalva, which is in free communication with the aortic root above the valve cusps; this may often result in paravalvar regurgitation directly to the left ventricular outflow tract. A true enclosed abscess cavity very rarely, if ever, develops. Fistulous communication to other cardiac chambers is well recognised. ${ }^{9}$

\section{Microbiology}

Three of Chaturvedi et al's patients were infected with Staphylococcus aureus and two with Streptococcus pneumoniae; both virulent aggressive pathogens capable of attacking a normal valve as well as one that is structurally abnormal. Three of their patients (who all had native valve infection) had no underlying cardiac defect detected and the other two had bicuspid aortic valves. While virulent organisms that infect native aortic valves almost always cause root abscesses, less virulent bacteria including viridans streptococci (and many others) may also do so, particularly if there is diagnostic delay. Early prosthetic valve endocarditis is very uncommon, is caused by skin organisms, and carries a very high mortality. Late prosthetic valve endocarditis is caused by the same organisms as native valve endocarditis and carries an intermediate mortality (which is organism dependent) between that of early prosthetic valve infection and native valve endocarditis.

\section{Clinical features}

Clinicians are well versed in suspecting aortic root abscess in infective endocarditis. It should be suspected in any patient with aortic valve endocarditis who fails to improve within 72 hours on appropriate antibiotics, particularly with prosthetic valve infection. Persistence or recrudescence of fever, persistently raised white blood cell counts, and other markers of systemic inflammation such as raised $\mathrm{C}$ reactive protein, or the development of cutaneous manifestations or embolic phenomena while on treatment all indicate uncontrolled infection. A lengthening PR interval on the surface ECG or development of heart block are particularly worrying features, and in the preechocardiographic era determined the need for urgent surgery. In suspected or proved prosthetic valve infection, any of these features indicated failed medical treatment, and a root abscess should be assumed until proved otherwise.

\section{Transoesophageal echocardiography}

Transoesphageal echocardiography is now the imaging method of choice for most cases of infective endocarditis and is mandatory in suspected prosthetic valve endocarditis. It offers particular advantages in the diagnosis of complications of endocarditis in the aortic root and the area of the aortic-mitral intervalvar fibrosa. ${ }^{11}$ Transthoracic echocardiography can give useful information about vegetations, ${ }^{12-16}$ the haemodynamic consequences of valvar regurgitation, and aortic root abscess. ${ }^{16}{ }^{17}$ However, transoesophageal echocardiography has the advantages of proximity of the transducer to the heart and a higher signal to noise ratio. A particular advantage in prosthetic aortic valve endocarditis is that from the transthoracic approach, the posterior part of the valve ring lies in the far field in the acoustic shadow of the aortic prosthesis. From the transoesophageal approach, this part of the heart is in the near field and is imaged with high resolution. Furthermore, transoesophageal echocardiography can provide useful anatomical definition of annular involvement, and whether the cavity extends to involve the subaortic curtain or upper interventricular septum, all important surgical considerations. In the series described by Chaturvedi et $a l,{ }^{10}$ transoesophageal echocardiography was used in only one case, but their patients were infants and children with native valve infection and excellent transthoracic windows. The technique only became available for the last patient of their series, but its advantages are now well recognised, even for children.

\section{Surgery}

Once an aortic root abscess is detected, urgent surgery is required as antibiotics alone will fail to control the infection and surgery can be curative. It is remarkable that surgery can succeed even in the face of positive blood and valve cultures, but it does and it should not be delayed while a "course" of antibiotics is given. Our policy is to provide adequate and appropriate antibiotic cover for 24 hours and then to operate. Delay is not only unhelpful but usually results in a more complex operation. The surgical mortality of all prosthetic valve endocarditis is high$20-50 \%$ in some series, and is highest in patients with aortic root abscess. ${ }^{18-21}$ Debridement of all infected and devitalised tissue is the mainstay of the surgical treatment of aortic root abscess. Several different surgical techniques have been advocated, including closure of the defect with a patch, ${ }^{22} 23$ implantation of a composite prosthetic valve conduit, ${ }^{324}$ aggressive debridement of the abscess cavity and surrounding tissue with reconstruction of the left ventricular outflow tract with autologous pericardium, ${ }^{25}$ translocation of the aortic valve, ${ }^{426}$ and extra-anatomical 
bypass of the aortic root. ${ }^{28}$ The feature common to all these operations is the use of synthetic material.

The use of biological material has clear advantages. Aortic valve homografts are particularly useful for several reasons: they enable the abscess cavity to be completely excluded from the circulation; they avoid the use of prosthetic material; and they are more resistant to infection than any other valve substitute. ${ }^{17}$ Finally, use of a homograft allows a flexible approach to the operation enabling - for example, the replacement of the entire anterior leaflet of the mitral valve in continuity with the aortic valve.

The risk of early postoperative infection for mechanical and bioprosthetic valves is higher than with homografts. ${ }^{29-31}$ On the basis of qualitative differences in the hazard function for recurrent endocarditis in the three types of valve substitute, the homograft emerges as the valve of choice for both native and prosthetic valve endocarditis. Yacoub et al used homografts to treat prosthetic aortic endocarditis in 48 patients over a 23 year period, of whom 28 had aortic root abscesses ${ }^{32}$; the operative mortality was $8.3 \%$. The actuarial survival at five years was $97 \%$ (confidence limits $84 \%$ to $100 \%$ ), and freedom from endocarditis at 10 years was $97 \%$. Excellent long term results can also be obtained by radical resection of the abscess and reconstruction of the heart with pericardium..$^{33}$ In a consecutive series of 70 patients with acute infective endocarditis and paravalvar abscess there were nine operative deaths. Only one patient had persistent infection and required reoperation. The actuarial survival including operative deaths was $64(8) \%$ at eight years and the freedom from recurrent endocarditis was $76(10) \%$ at eight years.

The choice of the particular homograft technique largely depends on accurate imaging of the anatomical details of the abscess. Operative technique is important and requires meticulous attention to detail. Interrupted sutures placed into normal tissue proximally in the muscle of the left ventricular outflow tract ensure that the homograft valve will be securely seated. Intraoperative transoesophageal echocardiography can help to ensure the integrity of the coronary anastomosis and the absence of turbulence, which may suggest distortion. It is important to avoid the use of any foreign material such as pledgets or cuffs of Dacron cloth. Two approaches can be used to implant a homograft valve: the first is to use the aortic valve and root together so that proximal and distal suture lines are placed to incorporate normal uninvolved left ventricular muscle and aortic wall. The aortic abscess is thus effectively excluded from the circulation. The second is to debride the abscess cavity and implant the homograft valve without incorporating root replacement, using a two-suture line technique to close the cavity. This can be achieved by placing the proximal suture line well below the abscess cavity, using interrupted fine sutures without tension. Some authors have advised the use of pulmonary autografts to provide a living graft, ${ }^{34}$ but this is controversial as the risks and benefits are finely balanced. A large operation involving the opening of many new tissue planes in a critically ill patient may not be desirable. Living valve tissue is more likely to be resistant to infection but a less viable valve (homovital or cryopreserved pulmonary homograft) must still be placed in the right ventricular outflow tract. It is unlikely that data will ever be available from a randomised trial to settle this issue and the decision will depend on the surgeon's individual experience and preference.

Operations for aortic root abscess are high risk procedures and require a coordinated approach. A heparin management system to provide precise titration of protamine with the use of aprotinin and a cell saver is becoming routine. If an aortic homograft is not available, a pulmonary homograft or a free standing gluteraldehyde preserved stentless valve can be used. The long term fate of both these valve options is unknown and they should be used cautiously. They may become aneurysmal and close observation with regular echocardiographic examination under supervision of a cardiothoracic surgeon is mandatory. Postoperative antibiotic management should be coordinated between microbiologist, surgeon, and cardiologist. If the valve is sterile when excised, the need for antibiotics beyond one week is questionable, and if bacteria are recovered from the excised valve, two weeks' intravenous antibiotics should suffice. The surgeon and cardiologist may not be as brave as the microbiologist in this respect, but if the infected tissue has not been eradicated, then antibiotics will not prevent the inevitable recurrence of infection.

\section{Conclusions}

Aortic root abscess is a life threatening complication of both native and prosthetic valve infection, which requires coordinated and experienced management. The cardiologist, microbiologist, and surgeon should consult frequently and closely to plan preoperative antibiotic cover, the timing and strategy of surgery, and postoperative management. Despite this, mortality remains higher than for many malignant diseases.

Consultant Cardiologist, St George's Hospital,

S J D BRECKER

Blackshaw Road, London SW17 0QT, UK

J R PEPPER

Reader in Cardiothoracic Surgery $\mathcal{E}$

Honorary Consultant Cardiothoracic Surgeon,

Royal Brompton $\mathcal{E}$ Harefield NHS Trust,

Sydney Street, London SW3 6NP, UK

Professor in Clinical Microbiology, Division of Infection,

S J EYKYN

St Thomas's Hospital, Lambeth Palace Road,

London SE1 7EH, UK

1 Donaldson RM, Ross DM. Homograft aortic root replacement for complicated prosthetic valve endocarditis. Circulation 1984;70(suppl I):I-178-81.

2 Bailey WW, Ivey TD, Miller DW Jr. Dacron patch closure of aortic annulus mycotic aneurysms. Circulation 1982;66(suppl I):I-127-30.

3 Frantz PT, Murray GF, Wilcox BR. Surgical management of left Frantz PT, Murray GF, Wilcox BR. Surgical management of left
ventricular-aortic discontinuity complicating bacterial endocarditis. Ann ventricular-aortic discontin.
Thorac Surg 1980;29:1-7.

4 Reitz BA, Stinson EB, Watson DC, et al. Translocation of the aortic valve for prosthetic valve endocarditis. F Thorac Cardiovasc Surg 1981;81:212-18.

John RM, Pugsley W, Treasure T, et al. Aortic root complications of infective endocarditis - influence on surgical outcome. Eur Heart f 1991;12:241-8. 6 Kirkin JW, Barratt-Boyes BG. Aortic valve disease. In: Kirklin JW, Barratt-Boyes BG, eds. Cardiac surgery. New York: Wiley, 1986:373-429.

7 Kirklin JK, Kirklin JW, Pacifico AD. Aortic valve endocarditis with aortic root abscess cavity: Surgical treatment with aortic valve homograft. Ann Thorac Surg 1988;45:674-7.

8 Zwischenberger JB, Shalaby TZ, Conti VR. Viable cryopreserved aortic homograft for aortic valve endocarditis and annular abscesses. Ann Thorac Surg 1989;48:365-70.

9 Brecker SJD, Jin XY, Yacoub MH. Anatomical definition of aortic root abscesses by transesophageal echocardiography: planning a surgical strategy using homograft valves. Clin Cardiol 1995; 18:353-9.

10 Chaturvedi R, de Leval M, Sullivan ID. Urgent homograft aortic root replacement for aortic root abscess in infants and children. Heart 1999;81: replacem.

11 Karalis DG, Bansal RC, Hauck AJ, et al. Transesophageal echocardiographic recognition of subaortic complications in aortic valve endocarditis. Clinical and surgical implications. Circulation 1992;86:353-62.

12 Dillon JC, Feigenbaum H, Konecke LL, et al. Echocardiographic manifestations of valvular vegetations. Am Heart F 1973;86:698-704.

13 Stewart JA, Silimperi D, Harris P, et al. Echocardiographic documentation of vegetative lesions in infective endocarditis: clinical implications. Circulation 1980;61:374-80.

14 Robbins MJ, Frater RWM, Soeiro R, et al. Influence of vegetation size on clinical outcome of right-sided infective endocarditis. $\mathrm{Am}$ f $\mathrm{Med}$ 1986;80:165-71

15 Stafford WJ, Petch J, Radford DJ. Vegetations in infective endocarditis: clinical relevance and diagnosis by cross-sectional echocardiography. $\mathrm{Br}$ Heart $f$ 1985;53:310-13.

16 Jaffe WM, Morgan DE, Pearlman AS, et al. Infective endocarditis, 1983-1988: echocardiographic findings and factors influencing morbidity 1983-1988: echocardiographic findings and factors

17 Wong CM, Oldershaw P, Gibson DG. Echocardiographic demonstration of aortic root abscess after infective endocarditis. Br Heart $\mathcal{F}$ 1981;46:584-6. 
18 Miller DC. Predictors of outcome in patients with prosthetic valve endocarditis and potential advantages of homograft aortic root replacement for prosthetic ascending aortic valve-graft infections. F Cardiac Surg 1990;5 $53-62$

19 Tornos P, Sanz E, Permanyer-Miralda G. Late prosthetic valve endocarditis: immediate and long-term prognosis. Chest 1992;101:37-41.

20 Calderwood SB, Swinski LA, Karchmer AW. Prosthetic valve endocarditis: analysis of factors affecting outcome of therapy. $\mathcal{F}$ Thorac Cardiovasc Surg 1986;92:776-83.

21 Jault F, Gangjbakhch I, Chastre JC. Prosthetic valve endocarditis with ring abscess. Surgical management and long-term results. I Thorac Cardiovasc Surg 1993;105:1106-13.

22 Symbas PN, Vlasis SE, Zacharopoulos L, et al. Acute endocarditis: surgical treatment of aortic regurgitation and aortico-left ventricular discontinuity. F Thorac Cardiovasc Surg 1982;84:291-6.

23 Fiore AC, Ivey TD, McKeown PP, et al. Patch closure of aortic annulus mycotic aneurysms. Ann Thorac Surg 1986;42:372-9.

24 VanHooser DW, Johnson RG, Hein RA, et al. Successful management of aortic valve endocarditis with associated peri-annular abscess and aneurysm. Ann Thorac Surg 1986;42:148-51.

25 David TE, Komeda M, Brofman PR. Surgical treatment of aortic root abscess. Circulation 1989;80(suppl 1):I-269-74.

26 Danielson GK, Titus JL, Dushane JW. Successful treatment of aortic valve endocarditis and aortic root abscesses by insertion of prosthetic valve in ascending aorta and placement of bypass grafts to coronary arteries. $\mathcal{F}$ Thorac Cardiovasc Surg 1974;67:443-9.
27 Endo $M$, Nishida $H$, Imamura $E$, et al. Sutureless aortic valve replacement for peri-annular abscess due to active bacterial endocarditis: a new translocation. Ann Thorac Surg 1988;45:568-9.

28 Bove EL, Parker FB, Marvasti MA, et al. Complete extra-anatomic bypass of the aortic root: treatment of recurrent mediastinal infection. F Thorac Cardiovasc Surg 1983;86:932-4.

29 Agnihotri AK, McGiffin DC, Galbraech AJ. The prevalence of infective endocarditis after aortic valve replacement. 7 Cardiovasc Surg 1995;110: $1708-24$.

30 Haydock D, Barratt-Boyes B, Macedo T. Aortic valve replacement for active infectious endocarditis in 108 patients. A comparison of free-hand allograft valves with mechanical prostheses and bioprostheses. F Thorac Cardiovasc Surg 1992;103:130-9.

31 McGiffin DE, Galbraech AJ, McLachlan GJ. Aortic valve infection. Risk factors for death and recurrent endocarditis after aortic valve replacement. 7 Thorac Cardiovasc Surg 1992; 104:511-20.

32 Petrou M, Wong K, Albertucci M, et al. Evaluation of unstented aortic homografts for the treatment of prosthetic aortic valve endocarditis. Circulation 1994;90(suppl II):II-198-204.

33 d'Udekem Y, David TE, Feindel CM, et al. Long-term results of operation for para-valvular abscess. Ann Thorac Surg 1996;62:48-53.

34 Joyce SF, Tingle FFJ, Aagaard J, et al. The Ross operation in the treatment of native and prosthetic aortic valve endocarditis. F Heart Valve Dis 1994;3: 371-6.

\section{STAMPS IN CARDIOLOGY}

de Musset sign

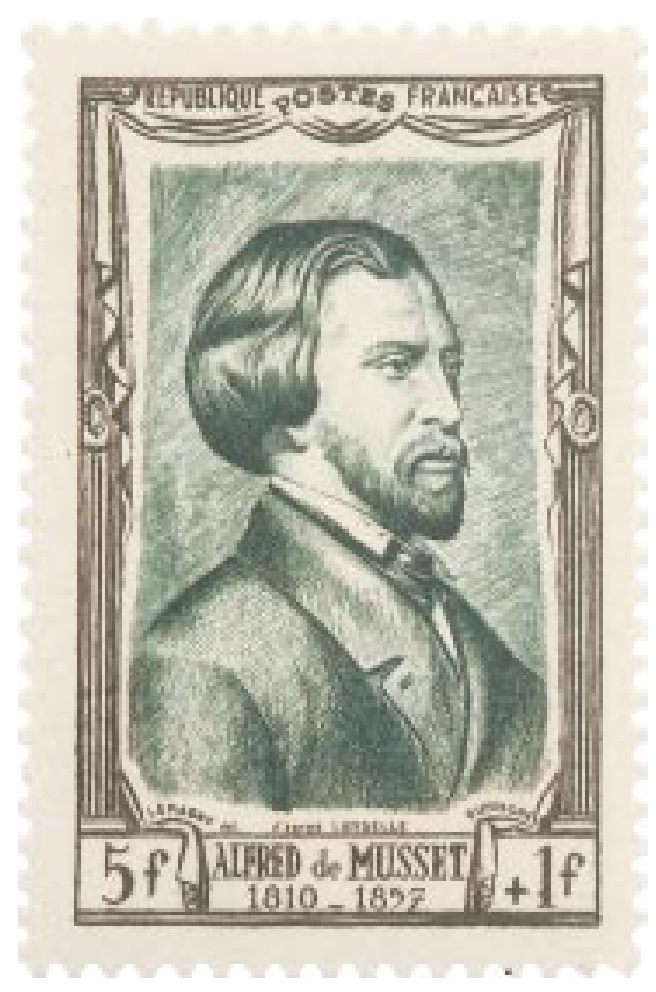

The de Musset sign is a visible nodding of the head in time with arterial pulsation in patients with aortic insufficiency. Alfred de Musset (1810-57) was a French poet. George Sand became his mistress but left him for Chopin. The sign was first described by his brother Paul in the biography he wrote about Alfred. Paul and his mother observed it while they were having breakfast in 1842. When told of this Alfred put his thumb and forefinger on his neck and the head stopped nodding. He said, "You see, this dreadful malady is cured by a method which is not only simple but inexpensive as well."

Alfred de Musset

Used to call his cat pusse

His accent was affected

That was to be expected.

Alfred de Musset appears on a French stamp from 1951. A set of six stamps was issued on 2 June 1951 depicting 19th century celebrities for the National Relief Fund charity. Other personalities shown on higher values were Gay-Lussac and Napoleon.

$M$ K DAVIES A HOLLMAN 